\title{
New Pathogenic Homozygous Variant in (DGOUK) Gene Cause Vital Progressive Liver Failure in a Neonate: Case Report
}

\author{
Maher Mohammed Al-Hatlani* and Sharifah Ahmed Othman \\ Department of Pediatrics, Imam Abdulrahman bin Faisal Hospital, Saudi Arabia
}

Submission: January 29, 2020; Published: February 07, 2020

*Corresponding author: Maher Mohammed Al-Hatlani, Department of Pediatrics, Imam Abdulrahman bin Faisal Hospital, Dhahran, Saudi Arabia

\section{Abstract}

Many heterogeneous groups of mitochondrial diseases of infants can lead to which called "Mitochondrial DNA depletion syndromes" (MDS), which mainly caused by reduction in the number of mtDNA and lead to impaired in the synthesis of respiratory chain complexes. It is inherited in mendelian fashion and it can be dominant or recessive traits. MDS is described first in 2001 by Mandel, he has been classified it into 2 groups; the hepatocerebral form which affecting the liver with central nervous systems, and the myopathic form, which affecting the skeletal muscle. Recently, there are three well-established forms known of MDS, by adding one more form to the previous classification; the encephalomyopathic form. Her we present a case of 3-month-old baby with a new homozygous variant c.763_766dup p. (Phe256*) discovered in DGUOK (OMIM:601465).

Keywords: Mitochondrial diseases; Hepatocerebral; Syndrome

\section{Introduction}

Many heterogeneous groups of mitochondrial diseases of infants can lead to which called "Mitochondrial DNA depletion syndromes" (MDS), which mainly caused by reduction in the number of mtDNA and lead to impaired in the synthesis of respiratory chain complexes. It is inherited in mendelian fashion and it can be dominant or recessive traits [1]. MDS is described first in 2001 by Mandel, he has been classified it into 2 groups; the hepatocerebral form which affecting the liver with central nervous systems, and the myopathic form, which affecting the skeletal muscle [2]. Recently, there are three well-established forms known of MDS, by adding one more form to the previous classification; the encephalomyopathic form [1]. One of the major causes of MDS is the mutation in the deoxyguanosine kinase (DGUOK) gene which associated with hepatocerebral syndrome [3]. which present with liver failure as they present in the first weeks of their life with hepatomegaly and neurologic manifestations such as hypotonia, nystagmus and psychomotor retardation. And represent in the patients by lactic acidemia and disorder in the function of respiratory chain [3]. It has a prevalence of 1 in each 20,000 infants can be affected by this disorder [4]. Her we present a case of 3-month-old baby with a new homozygous variant c.763_766dup p.(Phe256*) discovered in DGUOK (OMIM:601465).

\section{Case Report}

Our patient born at 37+1 weeks, with Apgar score (at 1st minute: 9, 5th minute: 10), Intrauterine Growth Restriction (IUGR) (weight: 1806gm, head circumference: 30 , height: $46 \mathrm{~cm}$ ), found to have on examination jaundice and cataract, with normal neurological, cardiology, musculoskeletal and genitourinary examination. All primitive reflexes were found. Found to have from birth, direct hyperbilirubinemia (Total Serum Bilirubin (TSB): $183.1 \mathrm{mg} / \mathrm{dl}$ "Reference range: $<=205.0 \mathrm{mg} / \mathrm{dl}$ " + Direct bilirubin (Bili D): 76.9umol/L "Reference range: <=8.6umol/L"), transaminity (Aspartate transaminase (AST): 104U/L "Reference range: 5-34U/L", Alanine transaminase (ALT): 81U/L "Reference range: 5-55U/L"), hypoalbunemia (Albumin (Alb): 25g/l "Reference range: 38-54g/l"), high Guanosine triphosphate (GTP): 256U/L “Reference range: 9-36U/L", Coagulation profile (International Normalized Ratio (INR): NA, Prothrombin Time (PT): NA, Partial Thromboplastin Time(PTT): 90 seconds "Reference range: 
32.0-55.2 seconds"), high Lactic Acid: $4.16 \mathrm{mmol} / \mathrm{L}$ "Reference range: $0.50-2.20 \mathrm{mmol} / \mathrm{L}$ ", high Ferritin $677.84 \mathrm{ug} / \mathrm{L}$ "Reference range: 4.60-204.0ug/L", high Ammonia 101umol/L "Reference range: 18-72umol/L”, hypoglycemia (Random Blood Glucose level: 2.5mmol/L "Reference range: 2.8"), Normal TORCH screen, Serum Amino Acid show elevation in (Tyrosine: 897umol/L "Reference range: 31.0-115.0umol/L", Glycine: 540umol/L "Reference range: 74.0-241.0umol/L", Alanine: 480umol/L "Reference range: 182.0-378.0umol/L", Citrulline: 74umol/L "Reference range: 16.0-32.umol/L", Threonine: 307umol/L "Reference range: 66.0-182.0umol/L", Phenylalanine: 104umol/L "Reference range: 29.0-85.0umol/L”, Histidine: 183umol/L "Reference range: 55.0-115.0umol/L”), bile acid : 81umol/L "Reference range: <= $6.0 \mathrm{umol} / \mathrm{L}$, Urine for organic acids excluded inborn errors of me- tabolism ( Methylmalonic Aciduria (MMA), Glutaric Aciduria Type 1 (GA-1), Propionic Aciduria (PA), 3-Methylcrotonyl-CoA Carboxylase (3MCC), 3-Methylglutaconic Aciduria, Maple Syrup Urine Disease (MSUD), Ethylmalonic Aciduria, 3-Hydroxy-3-Methylglutaryl-CoA Lyase (HMG) Multiple Acyl CoA Dehydrogenase Deficiency (MADD), Medium Chain Acyl CoA Dehydrogenase (MCAD) and Very Long Chain Acyl CoA Dehydrogenase (VLCAD) ) were excluded.

Screen for Congenital Adrenal Hyperplasia (170HP), Biotinidase deficiency (BTD), Congenital hypothyroidism (TSH) and Galactosemia (GALT) and Tyrosenamia, is done. Tandem MS were normal except for Methionine was high, may that secondary to liver disease. (Table 1).

Table 1:

\begin{tabular}{|c|c|c|}
\hline & At birth & 2-month-old "At admission" \\
\hline TSB & $183 \mathrm{mg} / \mathrm{dl}$ & $62.7 \mathrm{mg} / \mathrm{dl}$ \\
\hline Bili D & $76.9 \mathrm{umol} / \mathrm{L}$ & $35.4 \mathrm{umol} / \mathrm{L}$ \\
\hline AST & $104 \mathrm{U} / \mathrm{L}$ & $131 \mathrm{U} / \mathrm{L}$ \\
\hline ALT & $81 \mathrm{U} / \mathrm{L}$ & $124 \mathrm{U} / \mathrm{L}$ \\
\hline Alb & $25 \mathrm{~g} / \mathrm{l}$ & $29 \mathrm{~g} / \mathrm{l}$ \\
\hline GTP & $256 \mathrm{U} / \mathrm{L}$ & $366 \mathrm{U} / \mathrm{L}$ \\
\hline INR & NA & $>9.0 \mathrm{~seconds}$ \\
\hline PT & NA & $>94.0 \mathrm{~seconds}$ \\
\hline PTT & $90.0 \mathrm{~seconds}$ & $>60.0 \mathrm{~seconds}$ \\
\hline Lactic Acid & $4.16 \mathrm{mmol} / \mathrm{L}$ & $5.50 \mathrm{mmol} / \mathrm{L}$ \\
\hline Hgb & $179 \mathrm{gm} / \mathrm{L}$ & $138 \mathrm{gm} / \mathrm{L}$ \\
\hline Ferritin & $677.84 \mathrm{ug} / \mathrm{L}$ & $\mathrm{NA}$ \\
\hline Ammonia & $101 \mathrm{umol} / \mathrm{L}$ & $45 \mathrm{umol} / \mathrm{L}$ \\
\hline Bile Acid & $81.0 \mathrm{umol} / \mathrm{L}$ & $>200.0 \mathrm{umol} / \mathrm{L}$ \\
\hline Random Glucose Blood & $2.5 \mathrm{mmol} / \mathrm{L}$ & $5.6 \mathrm{mmol} / \mathrm{L}$ \\
\hline
\end{tabular}

\section{Table 2:}

\begin{tabular}{|c|c|c|c|c|c|c|}
\hline Gene (Isoform) & $\begin{array}{c}\text { OMIM-P } \\
\text { (Mode of Inheri- } \\
\text { tance) }\end{array}$ & Variant & Zygosity & $\begin{array}{c}\text { MAF } \\
\text { gnomAD [\%] }\end{array}$ & Literature [PMID] & Classification \\
\hline DGOUK & 251880 (AR) & $\begin{array}{c}\text { c.763-766dup } \\
\text { p.(Phe256*) } \\
\text { chr2: } 74185326\end{array}$ & hom. & 0.002 & 14568816, & 17073823, \\
(NM_080916.2) & & & 19265691 & Pathogenic \\
\hline
\end{tabular}

Since then, patient deteriorated with time with progressive liver failure, manifestoed by: sever coagulopathy (INR>9.0 seconds). Ascites, with one attack of SBP (gram negative bacilli, heavy growth of pseudomonas aeruginosa), Anemia as low as 68gm/L "Reference rang: 110-147gm/L" then Packed Red Blood Cells (PRBC) given (1 unit, 40ml), hypoglycemia, persistent lactic acid, then developed hepatorenal syndrome and encephalopathy stage II. WES done at age of 2 months by BIOSCIENTIA Institu fur Mediz- inische Diagnostik GmbH, Ingelheim Germany, as result showing in (Table 2). There was homozygous variant c.763-766dup p. (Phe256*) in DGOUK (OMIM:601465). Which leads to a stop gain, resulting in a premature stop codon, and subsequent mRNA degeneration (nonsense-mediated decay) or truncation of the protein. The variant has already been described in the literature in a family with mitochondrial hepatopathy (PMID: 14568816, $17073823,19265691)$. The variant is found in $0.002 \%$ of the over- 
all population ( 5 heterozygous, 0 homozygous; gnomAD) and this is the first time this mutation detected in the internal database in homozygous state. Considering the available information, the variant is classified as pathogenic. Patient at age of 3 months develop cardiopulmonary arrest and passed away.

\section{Discussion}

The main role of the mitochondria in our body is producing energy from the metabolism process to meet the cells' demand in ATP form. This is called oxidative phosphorylation (OXPHOS) process which need two genomes to be performed; nuclear and mitochondrial DNA (mtDNA). And this genome composed of many molecules, any mutations can give one of the disorders of mitochondrial, which either caused by alternations in the pools of nucleotides that needed for synthesis of mtDNA or alternations of enzymes that has direct role in mtDNA replication [5]. One of the most common forms of mutations of childhood respiratory chains is mtDNA reduction copy number which link with various clinical presentations. Recently, there are three forms of mtDNA depletion; hepatocerebral, encephalomyopathic and myopathic. (1) MDS is affect about 1 in each 20,000 infants [4]. A study done by Cormier-Daire V in 1997 [6], which consist of 1041 children; 22 (10\%) out of 234 patients with respiratory chain deficiency associated with liver failure, while 10 patients had liver dysfunction onset in the early neonatal period. The difficulty in the diagnosis and features variety from patient to another, can be underrate the exact prevalence of the MDS in general. Patients with MDS can present with many signs, the most common sign is hepatomegaly, which represent the progressive liver failure. And various symptoms such as vomiting, severe gastroesophageal reflux (GERD), delay in growth, or developmental delay. Liver function test on those patients usually reflect raising in serum alanine aminotransferase and aspartate aminotransferase, also coagulopathy profile will be affected, in addition to elevation in total and conjugated bilirubin Other neurological manifestations such as hypotonia, Leigh syndrome, nystagmus, psychomotor delay, pyramidal signs, seizures, and cataracts $[7,8]$. In our patient there are Intrauterine Growth Restriction (IUGR) with progressive liver failure. No neurological manifestations noted.

Histologically, in those patient's liver is recognized by macrovesicular and microvesicular steatosis, hepatocytic and canalicular cholestasis, fibrosis, and iron deposition in liver cells and sinusoidal cells [9]. In our patient, due to sever coagulopathies and age limitations, no liver biopsy done. One study done by Maciej Pronicki in 2011 [10], with review of biopsies and hepatic samples of patient's with MDS with hepatocerebral form (DGUOK) gene mutation, it found that the histopathological pattern of patients with DGUOK mutations showed typical diffuse scarring and neocholangliolisation which reflects liver failure in late stages. Furthermore, liver histology of DGUOK mutations patients in its early stages, showed classical cirrhotic pattern with prominent steatosis [11]. Management of the MDS in general is conservative manage- ment mostly. It is severe syndrome with bad prognosis in most of the cases. Currently, no available affective therapy, since there are multiple organs dysfunctions involvement. Also, involvement of multiple team from many different subspecialties should be work together to give the most benefit care and support with symptomatic management for those patients. Those patients may be managed with many options in aim of control the complications of this disorder; such as dietary modulation, cofactor supplementation, liver transplantation, and stem cell transplantation [11]. A very extensive regular evaluation should be done for these patients, for better understanding of organ failure and involvement of other systems such as he neuromuscular, hepatic, gastrointestinal, cardiac, and renal systems [11]. As the seizures are common in those patients as a one of the manifestations of neurological involvement, more than one anticonvulsant drugs with high doses are indicated to control the seizures attack. Also, to avoid muscle and joint contractures, physical therapy is necessary with chest physiotherapy to improve respiratory function with using of artificial ventilation methods [11]. Nutritional support in these disorders is very important, one of the suggestions to prevent hypoglycemic is to frequent feeding and use of uncooked cornstarch [12]. Liver transplantation is one of the management options in treatment of MDS. Infants of MDS with DGUOK gene mutation, liver transplantation has no role in increase the survival rate [11].

\section{References}

1. Spinazzola A (2011) Mitochondrial DNA mutations and depletion in pediatric medicine. Semin Fetal Neonatal Med 16(4): 190-196.

2. Di Re M, Sembongi H, He J, Reyes A, Yasukawa T, et al. (2009) The accessory subunit of mitochondrial DNA polymerase $\gamma$ determines the DNA content of mitochondrial nucleoids in human cultured cells. Nucleic Acids Res 37(17): 5701-5713.

3. Sezer T, Ozçay F, Balci O, Alehan F (2014) Novel Deoxyguanosine Kinase Gene Mutations in the Hepatocerebral Form of Mitochondrial DNA Depletion Syndrome. J Child Neurol 30(1): 124-128.

4. Skladal D, Halliday J, Thorburn DR (2003) Minimum birth prevalence of mitochondrial respiratory chain disorders in children. Brain 126(8): 1905-1912.

5. Spinazzola A, Zeviani M (2009) Disorders from perturbations of nuclear-mitochondrial intergenomic cross-talk. J Intern Med 265(2): 174-192.

6. Cormier-Daire V, Chretien D, Rustin P, Rötig A, Dubuisson C, et al (1997) Neonatal and delayed-onset liver involvement in disorders of oxidative phosphorylation. J Pediatr 130(5): 817-822.

7. Morris A, Taanman J, Blake J, Mark Cooper J, Lake B, et al. (1998) Liver failure associated with mitochondrial DNA depletion. J Hepatol 28(4): 556-563.

8. Labarthe F, Dobbelaere D, Devisme L, De Muret A, Jardel C, et al. (2005) Clinical, biochemical and morphological features of hepatocerebral syndrome with mitochondrial DNA depletion due to deoxyguanosine kinase deficiency. J Hepatol 43(2): 333-341.

9. Lee W, Sokol R (2007) Mitochondrial hepatopathies: Advances in genetics and pathogenesis. Hepatology 45(6): 1555-1565.

10. Pronicki M, Piekutowska-Abramczuk D, Rokicki D, Iwanicka-Pronicka K, Grajkowska W (2018) Histopathological liver findings in patients 
with hepatocerebral mitochondrial depletion syndrome with defined molecular basis. Pol J Pathol 69(3): 292-298.

11. El-Hattab A, Scaglia F (2013) Mitochondrial DNA Depletion Syndromes: Review and Updates of Genetic Basis, Manifestations, and Therapeutic Options. Neurotherapeutics 10(2): 186-198.
12. Parini R, Furlan F, Notarangelo L, Spinazzola A, Uziel G, et al. (2009) Glucose metabolism and diet-based prevention of liver dysfunction in MPV17 mutant patients. J Hepatol 50(1): 215-221.

\section{Your next submission with Juniper Publishers will reach you the below assets}

- Quality Editorial service

- Swift Peer Review

- Reprints availability

- E-prints Service

- Manuscript Podcast for convenient understanding

- Global attainment for your research

- Manuscript accessibility in different formats

( Pdf, E-pub, Full Text, Audio)

- Unceasing customer service

Track the below URL for one-step submission https://juniperpublishers.com/online-submission.php 